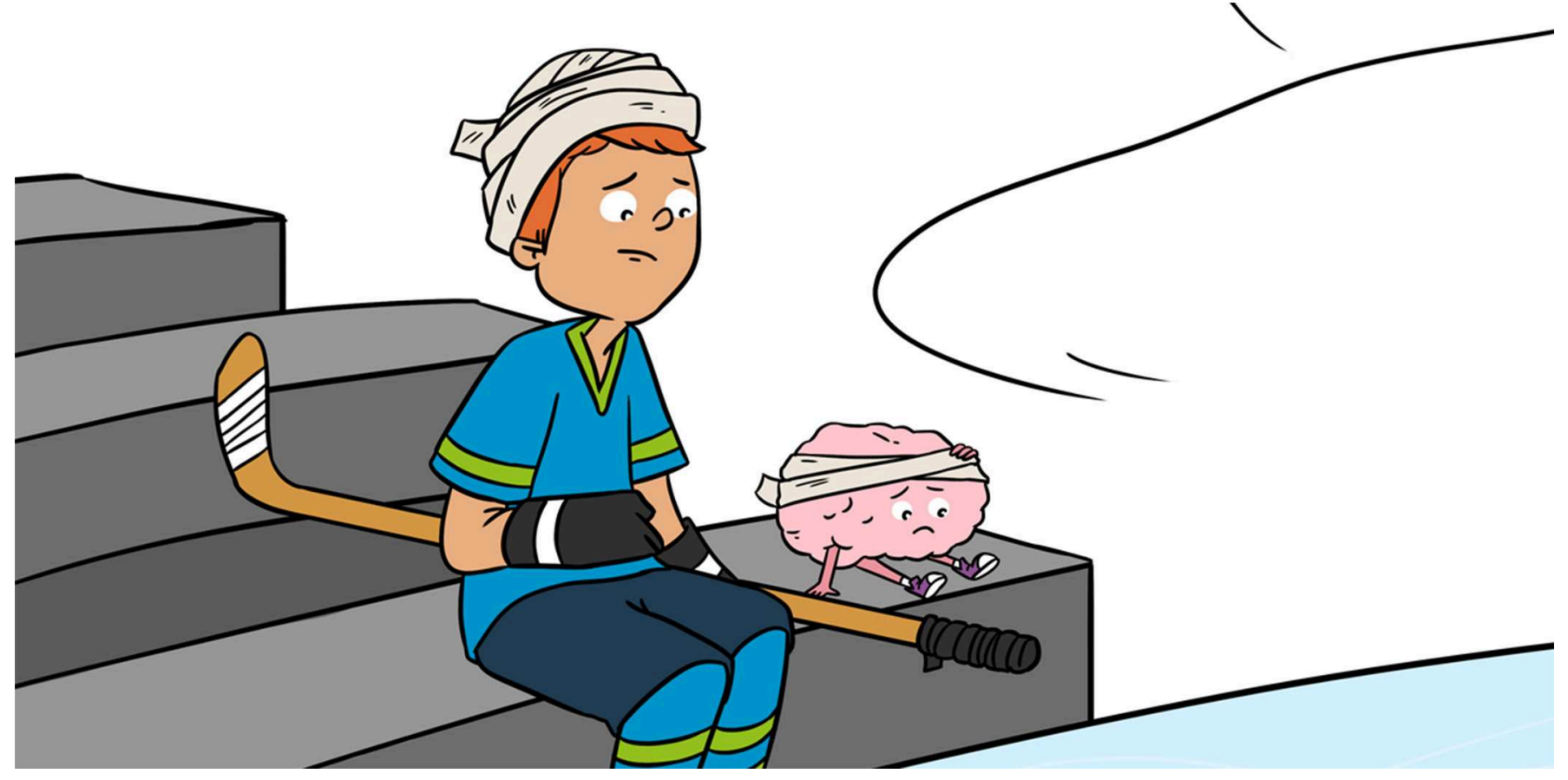

\title{
CTE: THE HIDDEN RISK OF PLAYING CONTACT SPORTS
}

Hamad Yadikar*, Connor Johnson, Edwin Mouhawasse, Milin Kurup, Lynn Nguyen, Niko Pafundi and Kevin K. W. Wang

Program for Neurotrauma, Neuroproteomics \& Biomarkers Research, Departments of Emergency Medicine, Psychiatry, Neuroscience and Chemistry, University of Florida, Gainesville, FL, United States

YOUNG REVIEWERS:

MONICA

AGE: 5

WASHINGTON

ELEMENTARY

AGES: 9-10
If you have ever played contact sports, you may have heard about chronic traumatic encephalopathy (CTE). CTE is caused by repetitive head injuries leading to a progressive loss in memory and other brain skills. The lack of proper skull protection has become a leading cause of brain problems in athletes. When playing sports, we focus on competition rather than the impact of repetitive injuries. Physical sports, like football, hockey, and boxing, have all been associated with CTE. When the brain hits the skull with an intense force, a substance in brain cells called tau proteins can malfunction in a way that leads to harmful changes in thinking, behavior, and mood. Tau proteins can collect between brain cells and form structures that disrupt normal communications between the cells. We can protect our brains from CTE by limiting the number of head injuries we experience. Giving ourselves adequate recovery time following an injury, receiving medical clearance before 
Figure 1

Which sports can cause CTE? High-impact sports, such as soccer, football, boxing, and hockey, can lead to the development of CTE.

Tackling in football, hitting the head on the ice in hockey, and hitting the ground or another person's head in soccer can all lead to head trauma and result in CTE if not appropriately treated. Although some protective gear has been created for sports, such as football and hockey, players are still susceptible to CTE. Sports administrators have added padding to arenas and courts to prevent head injuries. Additionally, coaches have emphasized good sportsmanship and proper techniques to avoid head injuries.

TRAUMATIC BRAIN INJURY (TBI)

Damage in the brain caused by a sudden hit to the head. TBIs can occur from accidents, sports, or other physical traumas.

\section{CHRONIC}

TRAUMATIC

ENCEPHALOPATHY (CTE)

A disease developed after multiple traumatic brain injuries, through the breakdown of brain cells.

\section{COUP AND}

COUNTERCOUP

MODEL

A model representing how an initial injury (coup) can have enough force to cause damage on the opposite side of the brain (countercoup).

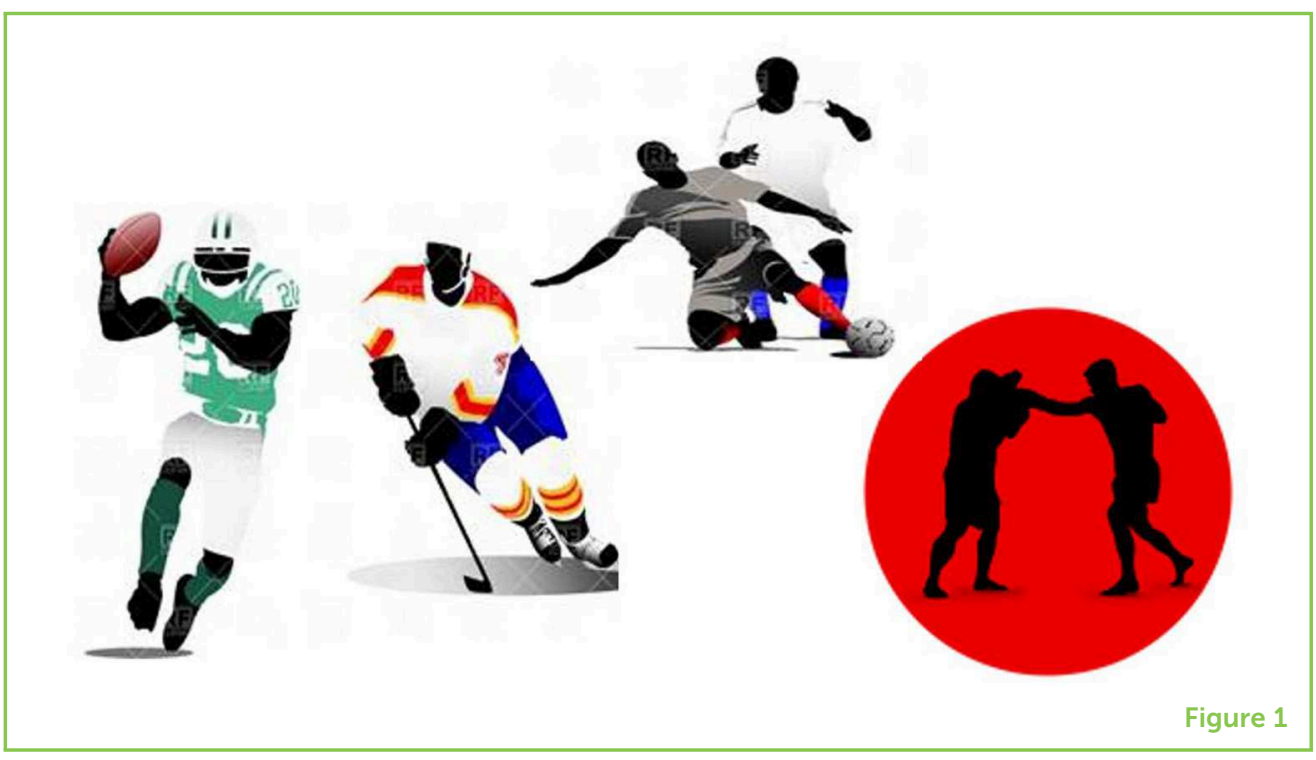

returning to normal activities, and keeping up with our social lives throughout recovery can help prevent or minimize the negative effects of CTE.

\section{WHAT IS CTE?}

Have you ever played a sport and hit your head by accident, maybe colliding with the ground or with another person? You might have experienced a ringing pain or a headache in the short term, but have you ever considered what repetitive hits to the head might do to your brain in the long term? When we play sports, we tend to focus on the fun parts, like the competition, teamwork, and the joy of winning. However, people usually do not consider the possible consequences of sports injuries on their mental health. Contact sports like football, soccer, boxing, as well as domestic violence and bomb blast waves, might damage the human brain more than expected, even after all the initial symptoms of the injury are gone (Figure 1) [1].

When a strong force hits the skull, the brain suffers damage. When the brain is damaged by a single injury, called a traumatic brain injury (TBI), the body is affected in many different ways, depending on the intensity of the damage. When there are repeated injuries to the brain, those people are at a higher risk for developing something called chronic traumatic encephalopathy (CTE). Chronic stands for "long-lasting," traumatic means "intense," and encephalopathy refers to any process that alters the function or the structure of the brain. Severe hits can injure opposite sides of the brain, through the coup and countercoup model. How do opposite sides of the brain get injured? Well, the coup is the initial injury that occurs from a hit, while the countercoup injury occurs on the opposite side of the brain as the brain hits the inside of the skull (Figure 2). When the injury is intense, 
Figure 2

One hit can damage two parts of the brain: the coup and countercoup model. One hit to the brain results in a force on the skull that causes the brain to move back and forth. This motion leads to dual injuries, one in the location of the initial hit (coup) and a secondary hit on the opposite side, where the brain bounces off the inside of the skull (countercoup). Such injuries can be very damaging to the structure and function of the brain $[1,2]$.

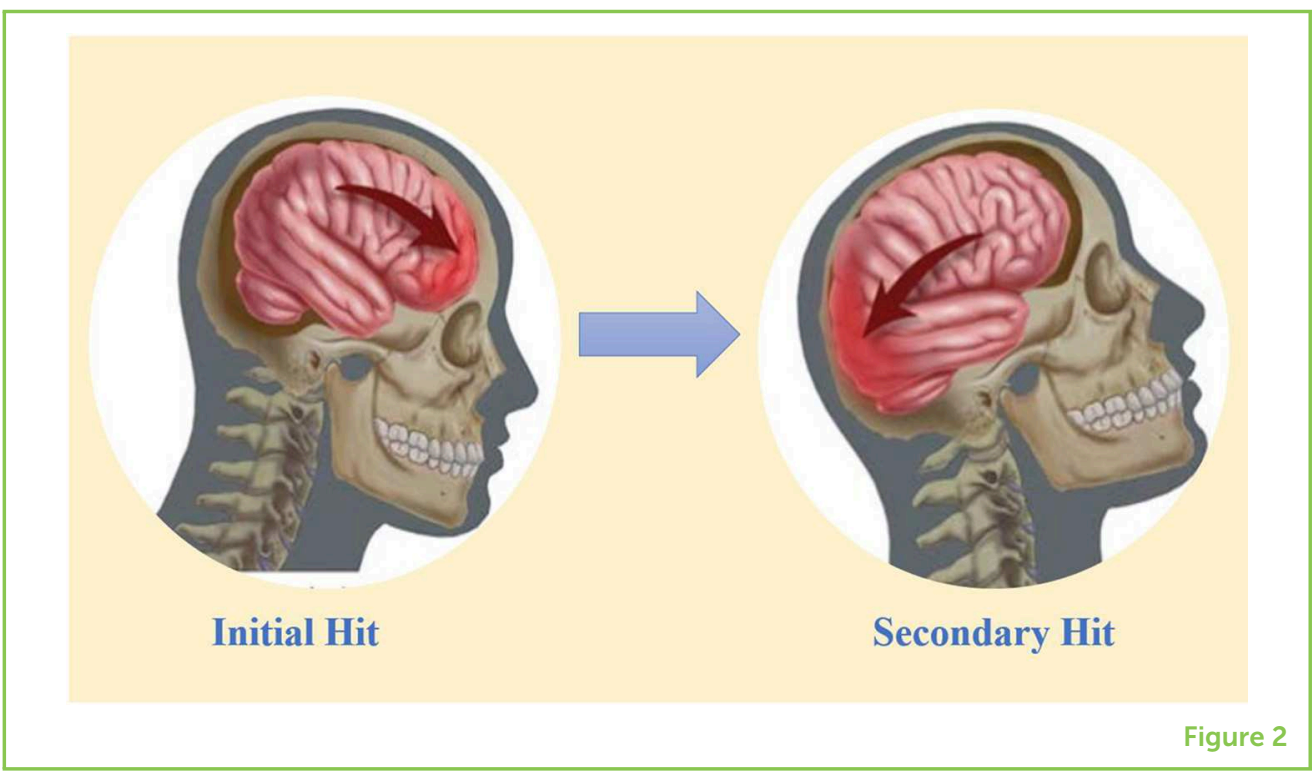

the brain can develop long-term damage in multiple areas that can significantly impair brain function, possibly leading to memory loss and, in a few cases, even death.

So, it seems that repeated brain injuries will begin to damage the brain permanently. In sports like football, players can have contact on almost every play. Head contact is frequent in soccer, especially when players slide tackle to get possession; frequent head-to-head contact going for a ball can knock players out. In boxing, getting hit in the head repeatedly is inevitable. Looking at these sports from this perspective, it is easy to see why so many athletes are developing CTE, and most do not realize the consequences. Some sports have less of a risk for $\mathrm{CTE}$, including swimming, tennis, and even basketball. We should all consider the risks and think about brain safety before we play any activity or sport. There are always emergencies that no one can control, like bike or car accidents, but when it comes to contact sports, we need to make the right decisions for a healthier life [1-4].

The level of intensity of each hit influences how quickly the brain starts to deteriorate. CTE can come from one strong hit or multiple smaller hits over time. Multiple factors influence the development of CTE in response to a head injury, including genes, diet, alcohol, drugs, etc. Different people are affected in different ways, and no specific number of hits dictates whether the CTE will develop [1].

\section{WHAT HAPPENS IN THE BRAIN WHEN PEOPLE HIT THEIR HEADS PLAYING SPORTS?}

The human brain needs healthy proteins for the brain cells to work and function properly. There are some proteins that we get from our diets and other proteins that are produced inside our bodies, such 
Figure 3

How do tau

proteins relate to

TBI/CTE? A brain sends

messages (synapses)

through brain cells or

neurons. A neuron is

made of a long central

strand known as an

axon, which helps carry

synapses in the brain.

An axon is made of

smaller proteins

(microtubules)

represented by the red and yellow balls. Similar to Lego pieces, tau protein holds onto the microtubules to hold the neurons together. When tau proteins are broken down as in TBI or CTE, they cause destruction of the brain neuronal structure. These broken parts of tau form a mess. Too much destruction makes it hard for the body to clean up the mess. When the messes obstruct brain functions, this leads to memory loss and other problems.

\section{TAU PROTEIN}

A protein that holds brain cells together to keep the brain structure intact.

\section{TAUOPATHIES}

Diseases caused by the breakdown of tau proteins; Alzheimer's disease is an example.

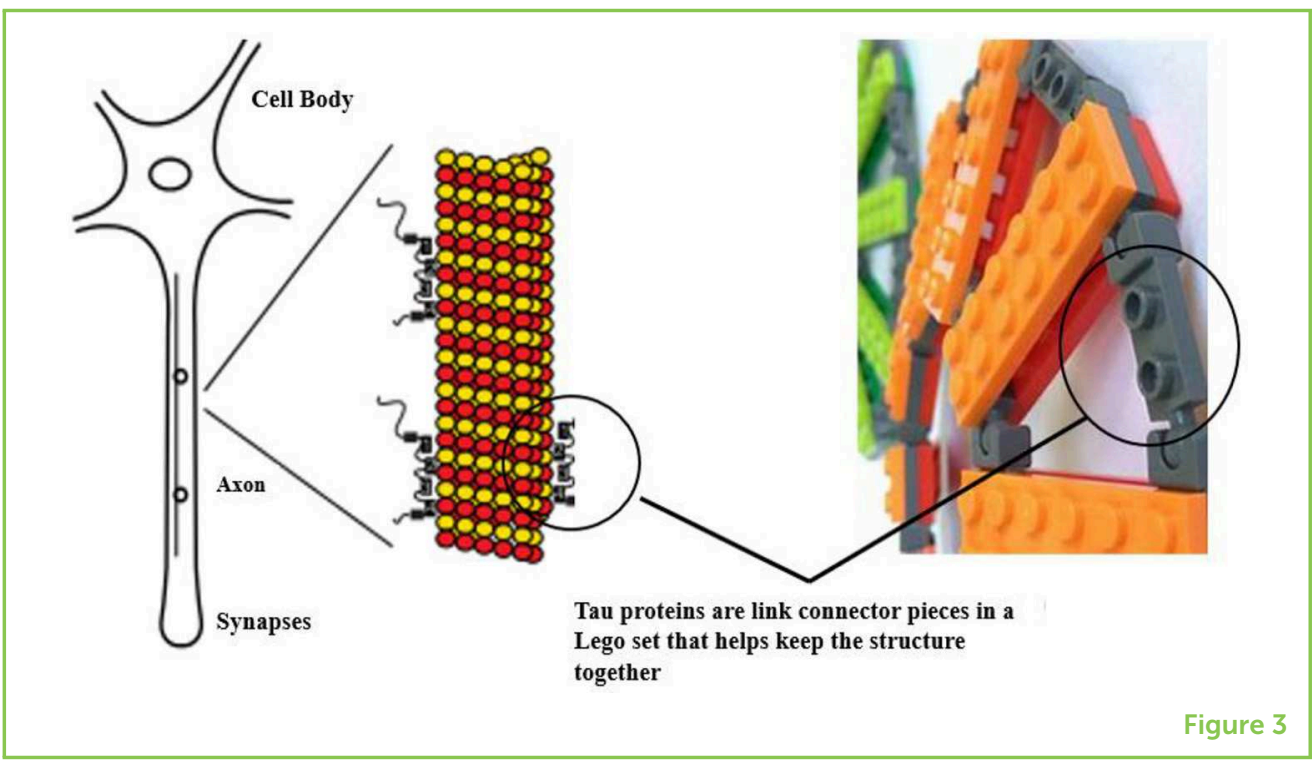

as the tau protein. Tau proteins are the connecting pieces that hold brain cells together. Imagine the brain is a Lego city, with thousands of tall buildings, each one representing a brain cell. If a head injury occurs while playing sports, it disrupts the brain cell structures, like an earthquake causing the Lego buildings to fall apart. Continuous hits shake the brain cells, breaking them into smaller pieces and creating a mess that we call protein aggregates. When these aggregates collect within cells, it is difficult for the tau protein to function properly. Think of a traffic jam on the streets between the Lego buildings, caused by all the fallen debris. Over time, larger protein aggregates collect through the breakdown of other brain cells. As people age, these messes become so severe that the Lego city of brain cells in the brain can no longer function in a healthy way. Diseases related to problems with tau function are called "tauopathies." Tauopathies do not occur in an instant but happen after multiple brain injuries occur over time. Playing contact sports can speed up this process [1, 2, 5] (Figure 3).

\section{HOW CAN I TELL IF I HAVE CTE?}

CTE is hard to diagnose compared with other brain diseases. The methods usually used to look at the brain and diagnose brain diseases are called MRI and CT scans [6]. Unfortunately, these techniques are not able to show whether or not the brain has experienced CTE. You can predict that a person might have CTE if he or she has been a sports player for 10-15 years and suddenly starts acting differently or expressing unusual emotions, such as suicidal thoughts and depression. Scientists usually identify CTE after death because the brain has to be removed and examined for tau clusters to accurately diagnose CTE. Observation of degraded brain structures and decreased brain size may indicate that a person had CTE. Most of the symptoms associated with CTE also occur in 
CEREBROSPINAL FLUID (CSF)

The brain or spine fluid that scientist use to study tauopathies. people who suffer from diseases related to memory loss, including Alzheimer's disease.

Researchers are trying to find new and efficient ways to diagnose CTE in living patients so that these people can be treated. Many methods are being studied, but one of the most promising methods is a brain-scanning technique known as positron emission tomography (PET). PET scans the brain a radioactive substance is injected into a vein. The radioactive substance allows any problems with the brain tissues to be seen. PET researchers would like to discover a specific radioactive substance that can find issues with the tau proteins in the brain. Another important method for diagnosing CTE involves identifying broken-down forms of tau in body fluids, including blood, cerebrospinal fluid (CSF), mucus, saliva, or urine. Detection of tau in these fluids could indicate whether CTE is likely in the patient.

How can you know if you might have a brain injury from hitting your head? Immediate symptoms, which can happen right after the injury or take up to a day to occur, include: loss of consciousness, feeling dizzy, severe headaches, blurry vision, nausea/vomiting, fatigue, trouble speaking, difficulty sleeping, loud ringing in the ears, or even a bad taste in the mouth $[3,4]$.

\section{CAN CTE BE TREATED?}

CTE is a progressive, long-term, harmful process. At this point, there no reliable treatments for CTE. However, scientists are hoping to find some biological molecules, known as biomarkers that can be used to detect and decrease the chances of developing CTE. These biomarkers are produced by the cells of the brain, specifically when the brain is injured, and they may someday allow us to diagnose CTE and potentially cure the diseased brain.

\section{HOW CAN I PREVENT MYSELF FROM GETTING CTE?}

Since there is no cure for CTE, preventing it is the best way to stop yourself from getting it. Headgear and body pads are examples of preventative methods that are meant to lower the chances of head injuries in many sports and jobs. Although helmets do not fully prevent TBI, they reduce the amount of impact. Hard surfaces on the outside of helmets are used to prevent skull fractures, while inner sections contain padding to reduce the amount of shock that the head experiences when hit. Scientists and sports medicine analysts are working on improving helmet paddings to prevent coup and countercoup injuries.

In addition to protective gear, sports administrators continue to take preventative measures to ensure the safety of players. For example, 
placing pads on hard surfaces in wrestling arenas and on basketball courts, to prevent head injuries. Coaches also teach players how to respect each other through sportsmanship, to avoid aggression and unnecessary injuries. Coaches have also incorporated neck stretches before, during, and after practice, to release neck tension and provide head support.

\section{CONCLUSION}

Although preventative methods are used, brain injuries still occur on a daily basis. When these injuries do happen, they must be appropriately treated. Around $85 \%$ of TBls need about 3 weeks of recovery. One should take care of oneself until fully recovered, to prevent additional injury. Cut back on physical activity, get plenty of rest, avoid computer time, write things down, and avoid drinking alcohol. During recovery, light exercise and brain-stimulating activities are recommended to help the brain and body heal. Some examples include stretching exercises and puzzles. Following the recovery process, your doctor may have you undergo physical and mental tests to make sure your brain has gone back to its original state. These tests will ensure that you have recovered enough before you to go back to your day-to-day activities [1, 2].

\section{REFERENCES}

1. Gaetz, M. 2017. The multi-factorial origins of chronic traumatic encephalopathy (CTE) symptomology in post-career athletes: the athlete post-career adjustment (AP-CA) model. Med. Hypotheses 102:130-43. doi: 10.1016/j.mehy.2017.03.023

2. Weston, S. 2015. School of Hard Knocks, Concussions by the Number, Center for Disease Control. Available online at: http://media.nj.com/hssportsextra/ photo/concussionmainjpg-03ef39e81af937e1.jpg

3. Aldag, M., Armstrong, R. C., Bandak, F., Bellgowan, P. S. F., Bentley, T., Biggerstaff, S., et al. 2017. The biological basis of chronic traumatic encephalopathy following blast injury: a literature review. J. Neurotrauma 34:S26-43. doi: $10.1089 /$ neu. 2017.5218

4. McKee, A., Stein, T. D., Kiernan, P. T., and Alvarez, V. E. 2015. The neuropathology of chronic traumatic encephalopathy. Brain Pathol. 25:350-64. doi: 10.1111/bpa.12248

5. Turner, R. C., Lucke-Wold, B. P., Robson, M. J., Omalu, B. I., Petraglia, A. L., and Bailes, J. E. 2012. Repetitive traumatic brain injury and development of chronic traumatic encephalopathy: a potential role for biomarkers in diagnosis, prognosis, and treatment? Front. Neurol. 3:186. doi: 10.3389/fneur.2012.00186

6. Donald, CLM., Mukherjee, P., and Yuh, E. 2019. How to See Into the Brain Without Surgery! Front. Young Minds. 7:14. doi: 10.3389/frym.2019.00014

SUBMITTED: 19 February 2019; ACCEPTED: 20 June 2019;

PUBLISHED ONLINE: 17 July 2019. 


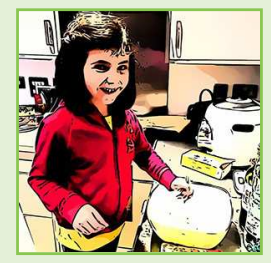

EDITED BY: Amy J. Markowitz, University of California, San Francisco, United States

CITATION: Yadikar H, Johnson C, Mouhawasse E, Kurup M, Nguyen L, Pafundi N and Wang KKW (2019) CTE: The Hidden Risk of Playing Contact Sports.

Front. Young Minds 7:93. doi: 10.3389/frym.2019.00093

CONFLICT OF INTEREST STATEMENT: The authors declare that the research was conducted in the absence of any commercial or financial relationships that could be construed as a potential conflict of interest.

COPYRIGHT @ 2019 Yadikar, Johnson, Mouhawasse, Kurup, Nguyen, Pafundi and Wang. This is an open-access article distributed under the terms of the Creative Commons Attribution License (CC BY). The use, distribution or reproduction in other forums is permitted, provided the original author(s) and the copyright owner(s) are credited and that the original publication in this journal is cited, in accordance with accepted academic practice. No use, distribution or reproduction is permitted which does not comply with these terms.

\section{YOUNG REVIEWERS}

\section{MONICA, AGE: 5}

I like to draw pictures... because I want to express what is on my mind. I enjoy going to new cities and countries. I am extremely creative, and I love cooking. I also like to read books and learn things by children all over the world. I like sports like swimming and skating.

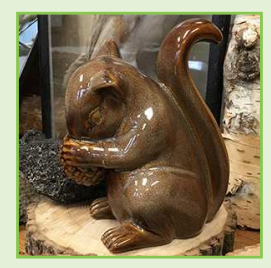

\section{WASHINGTON ELEMENTARY, AGES: 9-10}

This young group of science minded students love working together to solve problems think through issues and come up with solutions that make the world an even more awesome and science-y place!

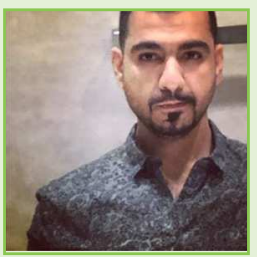

\section{AUTHORS}

\section{HAMAD YADIKAR}

Hamad Yadikar is an Assistant Professor at Kuwait University, in the Department of Chemistry and Emergency Medicine. His research project involves understanding traumatic brain injuries (TBIs), and CTE. He is continuing his studies as a post-doc with Professor Wang at the University of Florida and hopes to aim to find a cure for people that suffers from different types if brain injuries. *hamadayadikar@chem.ufl.edu 

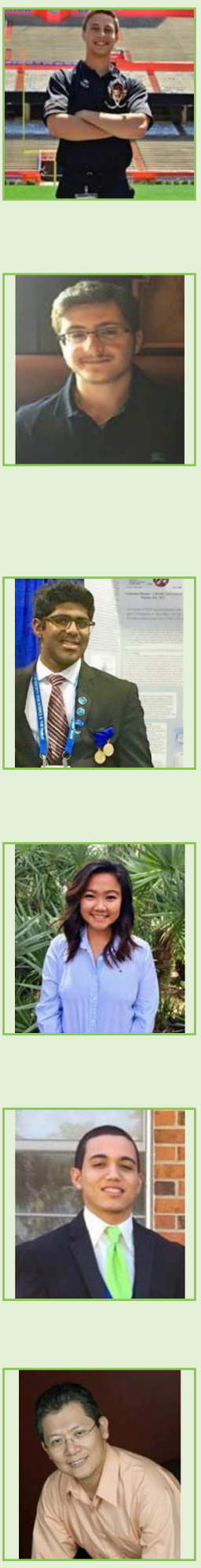

\section{CONNOR JOHNSON}

Connor Johnson is a fourth-year undergraduate at the University of Florida majoring in Chemistry with a focus on Biochemistry. He is a Researcher at the McKnight Brain Institute in Gainesville, Florida under the supervision of Dr. Kevin Wang, Ph.D. and Ph.D. candidate Hamad Yadikar. He hopes to attend medical school and ultimately become an emergency physician or a trauma surgeon.

\section{EDWIN MOUHAWASSE}

Edwin Mouhawasse is a third-year Health Science major at The University of Florida. $\mathrm{He}$ does research at the McKnight Brain Institute on traumatic brain injuries, under Ph.D. student Hamad Yadikar and Dr. Kevin Wang. He is a member of the volunteer organization Dream Team, where he volunteers in the pediatric intensive care unit and the pediatric cardiac intensive care unit. He is following the pre-medical track and would like to go to medical school and become a physician one day.

\section{MILIN KURUP}

Milin Kurup is a freshman studying at the University of Florida, majoring in Microbiology and Cell Sciences and minoring in Health Disparities. He has been working with Dr. Kevin Wang and Ph.D. candidate Hamad Yadikar on tauopathies for the last two years. After experience in neurological research, he hopes to pursue a career in Pediatric Neurosurgery and inspire children in medical sciences.

\section{LYNN NGUYEN}

Lynn Nguyen is in her fourth year studying at the University of Florida. She majors in Microbiology and Cell Science and minors in Environmental Sciences. She studies tauopathies at the McKnight Brain Institute under the supervision of Dr. Kevin Wang and Ph.D. candidate Hamad Yadikar. Once she graduates, she plans to apply to dental school and eventually become a prosthodontist.

\section{NIKO PAFUNDI}

Niko Pafundi graduated from the University of Florida with a B.S. in biology in 2018. Under the supervision of Dr. Kevin Wang and Ph.D. candidate Hamad Yadikar, he has assisted in experiments and analyzing the results to further understand tau protein. In May of 2018, he plans to apply to Pharmacy School.

\section{KEVIN K. W. WANG}

Dr. Kevin Wang is the Director of the Program for Neurotrauma, Neuroproteomics \& Biomarkers Research and Associate Professor of Emergency Medicine at the University of Florida and the McKnight Brain Institute in Gainesville, Florida, USA. $\mathrm{He}$ is also Health Research Neuroscientist and Merit Award Principal Investigator at the Brain Rehabilitation Research Center at the Malcom Randall VA Medical Center (Gainesville, FL). 